\title{
Tracing the Difference: A Geoarchaeological Approach to the Formation of a Neolithic Tell/Extended Site in Greece
}

\author{
Dimitris Kontogiorgos*
}

Department of Archaeology, University of Sheffield, Northgate House, Sheffield, UK

\begin{abstract}
This study presents a geoarchaeological investigation conducted in occupation deposits of the Neolithic site at Paliambela, in Northern Greece, which unusually comprises both a low tell and a flat/extended component. The analysis reveals relative sedimentary and stratigraphic similarity between the deposits broadly indicating similarities in the overall formational characteristics between the two parts of the site.
\end{abstract}

Keywords: geoarchaeology, site formation processes, Neolithic Tell/Extended site.

\section{INTRODUCTION}

Tell and extended settlements are two types of sites morphologically very distinct: in contrast to tells, which are the result of a cumulative process resulting in a hill-like type of site that rarely exceeds $2 \mathrm{ha}$, the extended sites occupy an area much larger than tells, up to 25 times larger. The picture of considerable continuity, spatial and temporal, that is often represented in the archaeological deposits of tell sites, clearly contrasts with the spatial and temporal discontinuity of the deposits at the extended settlements [1]. The extended type of settlement was already known from the Balkans [2,3]. Archaeological investigations in Greece recently revealed quite a few extended Neolithic sites, and the most complete example is Makriyalos, in the Pieria region, Northern Greece [4] while the formational differences between tell and extended sites can be understood on multiple levels [e.g., 5, 6, 7].

The current systematic excavation at the Neolithic site under study, namely Paliambela (Pieria region, Northern Greece) (Fig. 1), which unusually comprises both a compact tell and a flat-extended component, complements the other recent archaeological work in northern Pieria region [8]. The excavation on the tell has confirmed that occupation at Paliambela began in the Early Neolithic period (early $6^{\text {th }}$ millennium B.C.). Excavation during 5 seasons (2000-2004) has confirmed the presence of significant constructions, including Early Neolithic (?) pit-houses, Middle Neolithic rectangular houses, a Middle Neolithic circuit ditch and Late Neolithic circuit walls to the south-east, and other Middle Neolithic ditches to the north and north-west. Final Neolithic and Bronze Age patchy deposits were also detected to the southeast. Finally, test sections on the non-tell component of the site revealed Middle Neolithic and Late Neolithic ditches, as well as Late Neolithic pits [9].

A recent geoarchaeological study of ditch and pit deposits from the tell and non-tell components of the site indicated different organization of the activities represented in these

*Address correspondence to this author at the Department of Archaeology, University of Sheffield, Northgate House, Sheffield, UK; Tel: (+30) 210-7236-313; Fax: (+30) 210-72-50-584; E-mail: mitsaraskonto@hotmail.com

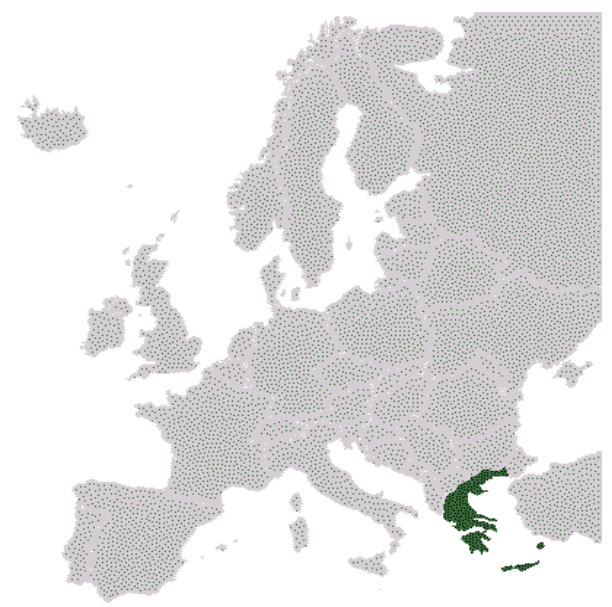

(a)

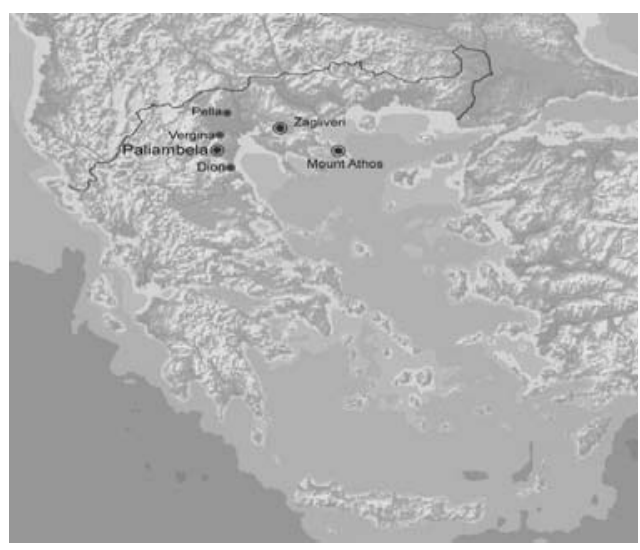

(b)

Fig. (1). a) Map of Europe, showing the location of Greece, b) Map of Greece, showing the location of Paliambela (Source: 'Paliambela excavation' archive).

contexts and, presumably, different organization of the living environment between the tell and the extended part of the site [10]. The present geoarchaeological study attempts to explore the formational characteristics of occupations deposits from the site, outside the boundaries of 'activity areas', as 


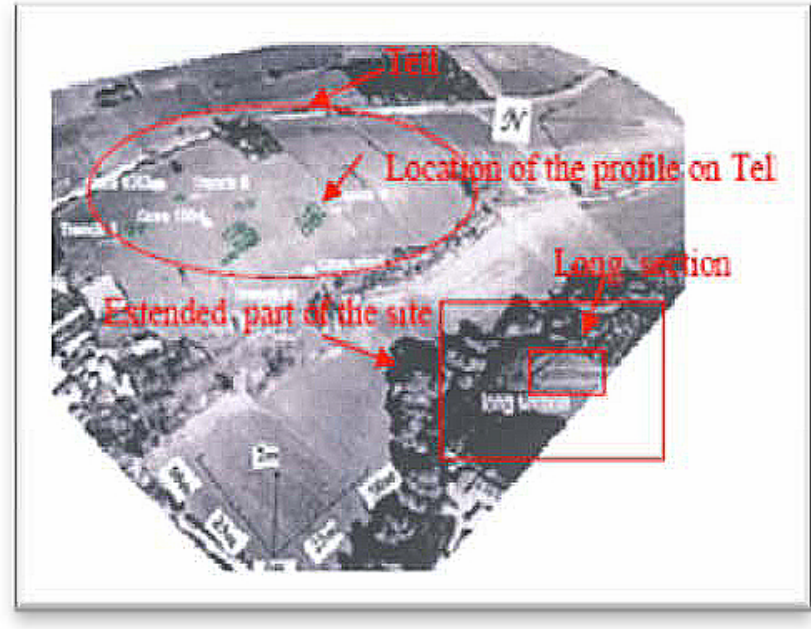

Fig. (2). Location of the Profiles on and off Tell (Source: 'Paliambela excavation archive').

are pits and ditches. The structure of this paper is as follows: Section 2 broadly describes the applied methodology; section 3 offers the results and interpretation, and finally section 4 presents the conclusions of this study.

\section{METHODOLOGY}

The samples used in the present study come from sampling two (2) relatively deep contexts comprising occupation deposits: one (1) from the tell component of the site and one (1) from the extended part of the Neolithic site (Fig. 2). Thirty nine (39) sediment samples were collected in columns at $5 \mathrm{~cm}$ vertical intervals on the profiles of the contexts, weighting ca $1500 \mathrm{~g}$ each. Four (4) methods were applied: (a) Particle-size analysis (hydrometer and sieve analysis), despite their disadvantages $[11,12]$, are widely used standard techniques, easy to perform, and relatively cheap and rapid. [13, 14]; (b) microartifact analysis [15, 16]; the laboratory procedure followed in microartifact analysis used two divisions of the phi ( $\phi)$ scale, that is $-2.00 \phi$ and $0 \phi$. Contents of the bulk samples were passed through a stack of $4 \mathrm{~mm}(-$ $2.00 \phi)$ and $1 \mathrm{~mm}(0 \phi)$ sieves. The material retained in the $1 \mathrm{~mm}$ sieve created the sub-sample that was processed for microartifacts and an optical microscope was used for identifications. Four microartifact categories were identified in the deposits from the Neolithic settlement: burnt clay (i.e., burnt specimens e.g., from mudbricks, wattle and daub constructions), shell (marine shells), bone (animal bone), and charcoal (charred organic particles); (c) magnetic susceptibility [17], and (d) organic Carbon determination, applying the dichromate method for organic carbon determination of soil organic matter [18]. Combination of these methods may provide insights into the formation of archaeological deposits that are subject to many different formation processes, while comparison of deposits, with partly common and partly distinctive depositional histories, may help disentangle problems of equifinality encountered in interpreting complex depositional processes.

\section{RESULTS AND INTERPRETATION.}

\subsection{Occupation Deposits on the Tell: Profile 1 (Figs. 3a/b- 4).}

Profile 1 was detected in Trench 9 on the SE facing slopes of the tell. The excavation exposed an $\mathrm{LN}$ enclosure wall partly overlying a MN ditch filled with deposits locally rich in ceramics and faunal debris. The stratigraphic sequence in the $\mathrm{E}$ face of trench 9 was approximately $1.40 \mathrm{~m}$ in depth and macroscopic examination revealed three basic stratigraphic units: bedrock; human occupation deposits; and a 'top-soil' layer, subject to recent ploughing and pedogenesis. Laboratory analysis confirmed the macroscopic examination. At the base of the sequence, coarse (i.e., muddy sandy gravel) layers without cultural inputs may be equated with the bedrock. The occupation deposits in the bulk of the analyzed part of the profile comprise a gravelly muddy sand rich in cultural inputs. At the top of the sequence, the topsoil layer is darker in colour and comprises slightly coarser gravelly mud, poorer in cultural inputs. The following discussion and analysis of Profile 1 is organized according to this tripartite division.

Zone 1 (from ca $140 \mathrm{~cm}$ to $\mathrm{ca} 100 \mathrm{~cm}$ ). Textural characteristics and lack of cultural inputs in this section of the profile demonstrate a very pale brown (10YR 7/3) culturally sterile gravelly muddy sand unit. The lack of cultural inputs in Zone 1 suggests undisturbed bedrock.

Zone 2 (from ca $100 \mathrm{~cm}$ to ca $20 \mathrm{~cm}$ ). Variations in microartifact density and the upwards rising trends in magnetic susceptibility and organic carbon content define two strati-

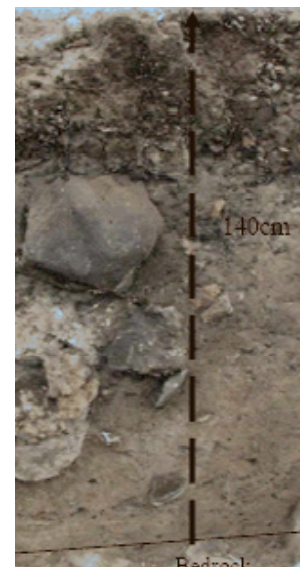

(a)

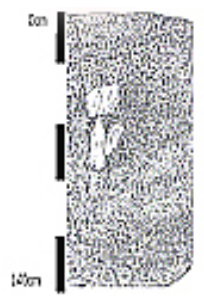

Key

Top soil layer dark grayish brown (10YR 4/2

: Occupation deposits; light brownish gray (10 YR. 6/2)

(b)

Fig. (3). (a) Profile 1 (View S-N, before sampling), (b) Profile 1-Field stratigraphy (View S-N) (Source: 'Paliambela excavation' archive). 
graphic units within Zone 2. The first unit (Zone 2a), from ca $99 \mathrm{~cm}$ to $\mathrm{ca} 60 \mathrm{~cm}$, consists of light brownish gray $(10 \mathrm{YR} 6 / 2)$ gravelly muddy sand including only modest amounts of microartifacts and upwards increases in magnetic susceptibility and organic carbon content. The second unit (Zone 2b), from ca $59 \mathrm{~cm}$ to ca $20 \mathrm{~cm}$, consists of light brownish gray $(10 \mathrm{YR}$ $6 / 2$ ) gravelly muddy sand exhibiting sharp increases and variability in microartifacts, accompanied by rising values in organic content and stable magnetic susceptibility. It is apparent that Zone 2 exhibits two sedimentary cycles. The first cycle is characteristized by low amounts of cultural micromaterials and gradual increases in magnetic susceptibility and organic carbon, suggesting anthropogenic activity. The variable trends in microartifacts, magnetic susceptibility and organic carbon in the second sedimentary cycle may be, at least partly, attributable to varying deposition of cultural materials, reflecting changing patterns of human activity at this part of the tell through time.

Zone 3 (from ca $19 \mathrm{~cm}$ to the top of the sequence). Zone 3 falls within the recent plough zone and comprises dark grayish brown (10YR 4/2) gravelly mud with moderate amounts of cultural inputs. This zone was noted in the excavation of nearby trenches, as the agriculturally disturbed top-soil layer, and the increases in organic carbon are consistent with the development of an A-soil horizon [19]. The modest values for cultural materials may reflect weathering of surface cultural materials exposed by ploughing.

Summary interpretation: Profile 1, apparently, spans the sequence from the culturally sterile gravelly muddy sand bedrock, through long term anthropogenic accretion of sediment and artifactual material, to the transformation of the abandoned occupation site. The laboratory analysis, not only confirmed the macroscopic observations and expectations, but added further detail to the depositional history of the site, as the recognition of two constituent sub-zones within Zone 2 of the profile. These sub-zones indicate significant increase and variation through time in both the volume and type of cultural inputs and sediment, reflecting changing patterns of human activity and sedimentary processes over time on SE part of the tell.

\subsection{Occupation Deposits on the Extended Part of the Neolithic Site Tell: Profile 2}

The small scale investigation with mechanical means in the floodplain to the south-east of the tell settlement revealed deep ditches and pits, that date from Middle to Late Neolithic, but also thick occupation deposits, alluvial deposits and the bedrock. The stratigraphic sequence of one profile (Profile 2) comprising occupation deposits outside the Tell settlement, was analyzed from the SE profile of the section (Fig. 5).

The stratigraphic sequence of Profile 2 was approximately $1.25 \mathrm{~m}$ in depth (Figs. 6a/b-7). The initial stratigraphic investigation indicated two stratigraphic units upon the bedrock: a dark brown layer characterized as an 'occupation surface', and a 'top-soil' layer that falls within the recent plough-zone.

The yellowish brown (10YR 5/4) gravelly sandy mud basal part of the sequence (Zone 1 , from ca $125 \mathrm{~cm}$ to ca $85 \mathrm{~cm})$ is the bedrock without cultural inputs. In Zone 2 (from ca $84 \mathrm{~cm}$ to ca $20 \mathrm{~cm}$ ) two sub-zones could be discerned: Zone 2a (dark grayish brown, 10YR 3/2) from ca $84 \mathrm{~cm}$ to $\mathrm{ca} 60 \mathrm{~cm}$ ) consists of slightly gravelly sandy mud, and very low amounts of cultural micro-materials; and Zone $2 \mathrm{~b}$ (from ca $59 \mathrm{~cm}$ to ca $20 \mathrm{~cm}$ ) comprising upwards fining (i.e., increases in clay) texture and similar increases in magnetic susceptibility, organic carbon and microartifacts The top-soil (dark grayish brown, 10YR 4/2) is identified from ca $29 \mathrm{~cm}$ to the top of the sequence. It exhibits stable texture,

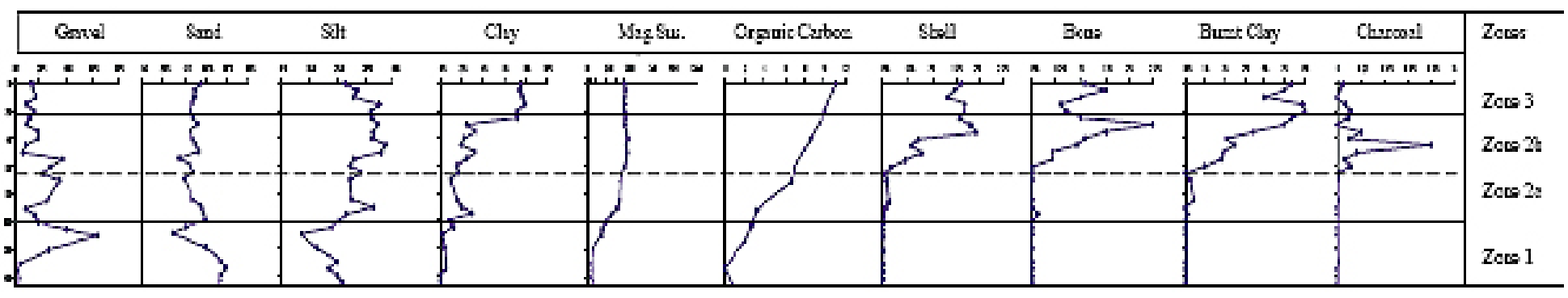

Fig. (4). Particle size analysis, magnetic susceptibility, organic carbon and microartifacts for Profile 1.

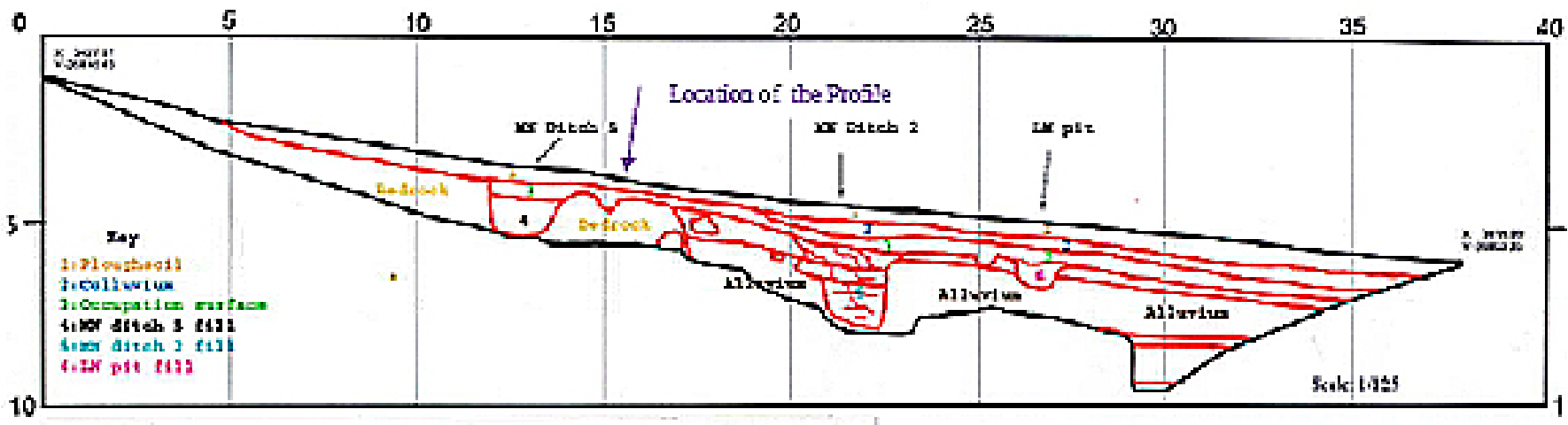

Fig. (5). Long Section-Field stratigraphy (south section, source: 'Paliambela excavation archive'). 


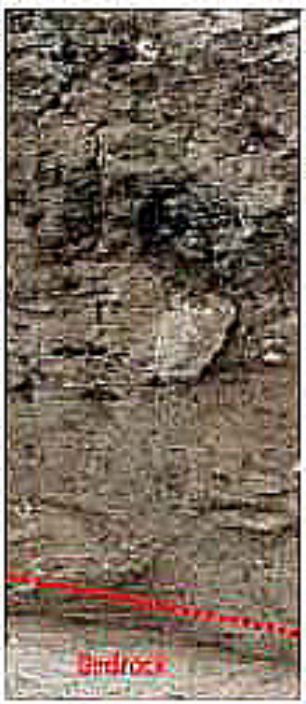

(a)

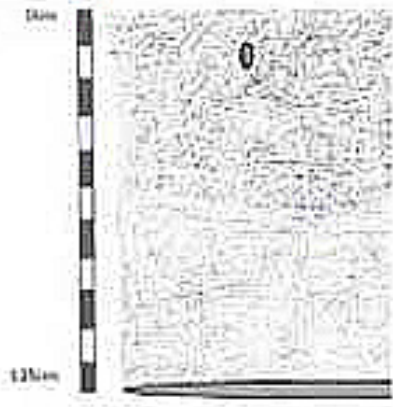

Dark arnyiti bown (loYR A/3)

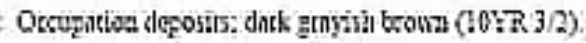

Bedrodi

(b)

Fig. (6). (a) Profile 2 (View S-N, before sampling), (b) Profile 2-Field stratigraphy (View S-N) (Source: 'Paliambela excavation' archive).

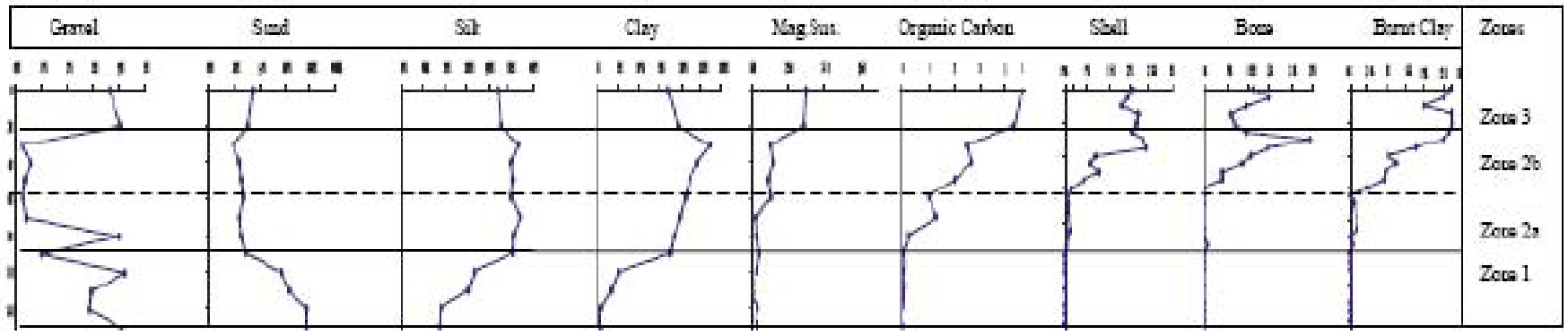

Fig. (7). Particle size analysis, magnetic susceptibility, organic carbon and microartifacts for Profile 2.

variable microartifacts and the highest organic carbon values in the sequence.

The fining upwards texture of Zone $2 b$ (and partly of Zone $2 \mathrm{a}$ ), denoted with the increases in clay content, is consistent with a slowing rate of sedimentation that contrasts with the peak in gravel, compatible with increased sedimentation at the bottom of Zone 2a. Most striking, however, is the increase in the input of cultural micro-materials in Zone 2 b. This increase, clearly contrasts with the low cultural content of Zone $2 \mathrm{a}$, possibly implying more intensive cultural use, and so variability in human activities taking place at this part of the site. Finally, in the 'top-soil' (Zone 3) the rising organic carbon is consistent with the development of an Asoil horizon [5]. The stable texture may be reflects homogenization of the layer due to ploughing while the variability in cultural materials in this zone may be reflects weathering of surface cultural materials exposed by ploughing.

Summary Interpretation: Profile 2 exhibits a pattern of fast sedimentation in the bottom part of Zone 2 (i.e., Zone 2a) giving way to slow sedimentation (i.e., upper part of Zone $2 \mathrm{a} /$ /Zone $2 \mathrm{~b}$ ). This sedimentation process is accompanied by low cultural input at the base of Zone 2 (i.e., Zone 2a) and irregular peaks in different cultural materials in the upper part of Zone 2 (i.e., Zone 2b) suggesting increased cultural use of this part of the site. The 'top-soil' (Zone 3) layer indicates the transformation of the abandoned site by modern agricultural practices.

\subsection{Traces of Difference?}

The analysis of the two profiles revealed, on a coarse temporal and spatial scale, that the surviving occupation deposits on the tell and the extended component of the Neolithic site exhibit relative sedimentary and stratigraphic similarity. This is most striking in two cases. Firstly, in Zones 2a, in both profiles, that exhibit common characteristics (i.e., low cultural input, low magnetic susceptibility and organic carbon content) and, secondly, in Zones $2 \mathrm{~b}$, in the two profiles, that again display broad similarities in the increases and variability in all the measured parameters. The presence of microartifacts (burnt clay, shell, bone and charcoal) indicates an anthropogenic contribution to formation of the occupation deposits while their significant variation (i.e., more evident in Zones $2 \mathrm{~b}$ in both Profiles) suggests variability in human activities in the two parts of the site. The surviving occupation deposits evidently built up sufficiently rapidly to bury and preserve variable concentrations of microartifacts.

Therefore, the results of the present study suggest that both the initial formation and the progressive development of the two parts of the Neolithic site, could be possibly attributed to similar types of depositional processes (i.e., low cultural input in the beginning of their use-life, giving way to increased and variable cultural deposition, and so, presumably, increased cultural activity, at some later stages of site development). 


\section{CONCLUSIONS}

The geoarchaeological analysis of the occupation deposits from the Neolithic site of Paliambela, revealed relative sedimentary and stratigraphic similarities, both temporal and spatial, in sediments and cultural indicators between the two parts of the site. The presence of microartifacts (burnt clay, shell, bone and charcoal) indicates an anthropogenic contribution to the formation of the deposits while their significant variation, later in their developmental process (i.e., Zones $2 \mathrm{~b}$ in Profiles 1 and 2), suggests differences in human activities but has not revealed more specific spatial information for differences in the organization of deposition of different types of cultural micro-materials.

In contrast to previous geoarchaeological analysis in pits and ditches from the site [15], that revealed spatial information for differences in the organization of deposition of different types of cultural micro-materials between different activity areas, this study was unable to detect this type of information. Thus, exploring the issue of differences between tell and extended settlements in contexts, other than those identified as 'activity areas', such as pits and ditches, requires more work on similar types of contexts. Nevertheless, the results of the present study are a step towards this goal.

\section{ACKNOWLEDGEMENTS}

I would like to express my deep appreciation and gratitude to Prof. Paul Halstead (University of Sheffield) and Professor Kostas Kotsakis (Aristotle University of Thessaloniki) for his encouragement to study the geoarchaeology of the site. Dr. Rozalia Christidou provided useful comments. Much of this study was generously funded by the Wiener Laboratory at the American School of Classical Studies at Athens.

\section{REFERENCES}

[1] Kotsakis K. What Tells Can Tell: Social Space and Settlement in the Greek Neolithic. In: Halstead P, Ed. Neolithic Society in Greece, Sheffield Studies in Aegean Archaeology 2. Sheffield, England: Sheffield Academic Press Ltd, 1999; pp. 66-76.
[2] Chapman J. The Early Balkan Village. In: Bökönyi S, Ed. Neolithic of Southeastern Europe and its Near Eastern Connections. Varia Arcaeologica Hungarica 2, Budapest 1989; pp. 33-53.

[3] French DH. Index of Prehistoric Sites in Central Macedonia. Greek: Ministry of Culture, Athens 1967.

[4] Pappa M, Besios M. The Makriyalos project: Rescue Excavations at the Neolithic Site of Makriyalos, Pieria, Northern Greece. In: Halstead P, Ed. Neolithic Society in Greece, Sheffield Studies in Aegean Archaeology 2. Sheffield, England: Sheffield Academic Press 1999; pp. 77-87.

[5] Andreou S, Kotsakis K. Prehistoric rural communities in perspective: the Langadas survey project. In: Doukelis P, Mendoni L, Eds. Structures rurales et sociétés antiques. Paris: Annales Littéraires de l'Université de Besancon 1994; pp. 17-25.

[6] Andreou S, Fotiadis M, Kotsakis K. Review of Aegean prehistory 5: the Neolithic and Bronze Age of northern Greece. Am J Archaeol 1996; 100: 537-597.

[7] Halstead P. Neighbours from Hell? The Household in Neolithic Greece. In: Halstead P, Ed. Neolithic Society in Greece, Sheffield Studies in Aegean Archaeology 2. Sheffield, England: Sheffield Academic Press Ltd, 1999; pp. 77-95.

[8] Besios M, Pappa M. Pydna. Katerini: Pieriki Anaptiksiaki 1995.

[9] Kotsakis K, Halstead P. Anaskafi sta Neolithika Paliambela Kolindrou. In: Arhaeologiko Ergo sti Makedonia kai sti Thraki. Thessaloniki, Greek Ministry of Culture 2004; pp. 407-415.

[10] Kontogiorgos D. Geoarchaeological and Microartifact Analysis of Archaeological Sediments. A Case study From a Neolithic Tell Site in Greece Nova Science Publishers, Inc 2008.

[11] Fieller NRJ, Flenley EC. Statistical analysis of particle sizes and sediments. Br Archaeol Res Ser 1987; 393: 79-94.

[12] Fieller NRJ, Flenley EC, Olbricht W. Statistics of particle size data. Appl Stat 1992; 41: 127-46.

[13] Soil Survey Staff. Soil taxonomy: A Basic System of Soil Classification for Making and Interpreting Soil Surveys. Agricultural Handbook No. 436. United States Department of Agriculture, U.S. Government Printing Office, Washington, D.C 1975.

[14] Folk RL. Petrology of Sedimentary Rocks. Austin: Hemphil 1980.

[15] Stein JK, Telster PA. Size Distributions of Artifact Classes: Combining Macro- and Micro-Fractions. Geoarchaeology 1989; 4(1): 130 .

[16] Kontogiorgos D, Leontitsis A. Micro-artefacts weight estimation by Genetic Algorithm minimisation. JAS 2005; 32: 1275-1282.

[17] Gale SJ, Hoare PG. Quaternary Sediments. Petrographic Methods for the Study of Unlithified Rocks. Halsted Press, Toronto 1991.

[18] Rowell DL. Soil Science: Methods and Applications. Harlow: Pearson Education 1994.

[19] Birkeland PW. Soils and Geomorphology. Oxford: Oxford University Press 1999.

(C) Dimitris Kontogiorgos; Licensee Bentham Open.

This is an open access article licensed under the terms of the Creative Commons Attribution Non-Commercial License (http://creativecommons.org/licenses/by-nc/3.0/) which permits unrestricted, non-commercial use, distribution and reproduction in any medium, provided the work is properly cited. 